\title{
THE PHENOMENAL-INTENTIONAL NATURE OF HAPPINESS: A CONTEMPORARY APPROACH TO EPICTETUS AND STOICISM
}

\begin{abstract}
Allan Arturo González Estrada
Escuela de Filosofía, Universidad Nacional

Resumen

Este presente artículo ofrece una comparación entre las ideas filosóficas del estoicismo y las ideas contemporáneas en filosofía de la mente, para entender la naturaleza de la intencionalidad y experiencia como un elemento fundamental en una teoría de la "felicidad". De esta manera se evalúan aspectos relacionados con una teoría fisicalista a partir de una idea basada en una visión de la intencionalidad-fenoménica, esto es, la idea que la intencionalidad depende de las características fenoménicas, de esta forma, un análisis de la psicología popular y actitudes proposicionales como una base contemporánea para reinterpretar la metafísica y epistemología estoica, en particular desde las ideas expuestas por Epicteto, es posible. Se concluye que esta interpretación puede aportar una base más sólida que la propuesta en las teorías representacionales como las defendidas por Michael Tye para entender la naturaleza de la representación y el cambio en la narrativa interna que sugiere el estoicismo como vía a la felicidad.
\end{abstract}

Palabras clave: felicidad, intencionalidad, carácter fenoménico de la experiencia, estoicismo, Epicteto.

\begin{abstract}
The present paper offers a contrast between the philosophical ideas of Stoicism and contemporary ideas in philosophy of the mind, to understand the nature of intentionality and phenomenal experience as a fundamental element in a theory of "happiness". The metaphysical foundation that I fallow is based on a physicalist approach in non-reductive terms, from a perspective derived from a phenomenal-intentionality program, that is, the idea that intentionality depends on its phenomenal characteristics, in this way, an analysis of popular psychology and propositional attitudes as a contemporary basis for reinterpreting metaphysics and stoic epistemology in particular from the ideas exposed by Epictetus is possible. It is concluded that an interpretation more in line with the phenomenal characteristics of intentionality can provide a solid base to understand the nature of
\end{abstract}


representation and the change in the narrative suggested by Epictetus rather than the representational theories such as those advocated by Michael Tye as the path to understand happiness.

Keywords: Happiness, Intentionality, Phenomenal Character of Experience, Stoicism, Epictetus.

\section{Introduction}

It is said that happiness is neither a warm puppy nor a warm gun, and yet, there is an attempt to put our hopes in pursuing happiness in external factors such as objects, persons, or things. The conception of happiness is very elusive. This is evident considering that through history, philosophers had suggested different standpoints on the meaning of happiness. I want however to propose a view in which happiness is understood as a mental state with phenomenological and intentional properties realized by the relevant brain states. The idea I contend could be sympathetic with the views held by the stoics, specifically Epictetus ${ }^{1}$. On this account, I pretend to compare the stoic viewpoint on the mind, the idea of the representation, and the phenomenal properties, with the way they can be understood in the actual framework of the philosophy of mind. Thereby, I will suggest that the thesis of understanding today's complex metaphysics of the mind, and a theory of happiness whose roots are founded in the stoicism can be

1 Epictetus (AD 55-135, Nicopolis), was a Greek philosopher associated with the early Stoicism. defended. Incidentally, we should be clear on the fact that if we must dive deep into a theory of happiness, we must first establish its origin. That is, defining a starting point, developing the required discussion, and offering a plausible conclusion.

The position that I will explore lies on the fact that, if happiness is no the exclusive result of nurturing the character by our owns means (À la Aristotle $)^{2}$, then, it must be considered

2 For instance, Plato argues in the Republic that living in justice may result in happiness. Plato states that, "We have proved that justice in itself is the best thing for the soul itself" (Plato $10.612 \mathrm{~b})$. Justice in the platonic point of view is to live in harmony, and this harmony rooted in a mathematical idea is quite restrictive, this is, if you leave your natural place, there is no harmony, thus not justice. Another philosopher who explored the idea of happiness is Aristotle, who claims that eudaimonia ( $\varepsilon \dot{\delta} \delta \alpha \mu$ ovía) is to live according to virtue. Hence, by mean of this "human flourishing" (Rasmussen 1-2) via the exercise of habits, and then virtues, the life must lead us to focus on the contemplation of philosophical truths According to Aristotle, we must dedicate ourselves to practice virtue. By this mean, we shape our character to the main goal of human life which is this human flourishing. However, I may not totally agree with the Aristotelian viewpoint. The critique that Gregory Trianosky made about Aristotle may have some sense in the view that I explore:

...although one's attitudes, emotions, reactive capacities, and skills are or can to some 
the external factors that may appear in our lives, and the way they affect us. Thus, as Trianosky asserts, it is not the exercise of the agent on its own; instead, what it may be important is, as David Lewis observes, the history and the evidence of the agent (Lewis, Radical Interpretation 337).

In order to have a history of evidence and cognition, we must require a brain to store all the elements that configure our history and our character ${ }^{3}$ (our memories, hopes, beliefs, fears and so on) On this account, I will discuss the idea that happiness has its foundation in the phenomenal and intentional nature of the mind ${ }^{4}$. This proposal

extent be developed by will, no effort of will, however sustained, is sufficient for their development. Character is the product not only of voluntary action but also of the activity of temperament, along with upbringing, childhood experiences, social environment, peer expectations, and pure happenstance. And not only temperament but all of these things are not themselves the product of some exercise of agency, whether voluntary or non-voluntary. Hence, no Aristotelian account of responsibility for character can succeed(104).

Moreover, Aristotle suggests that some external goods are required in addition to virtue for happiness, but my view is that this idea could be highly problematic. How an external object can give us a sense of security?

3 According to Kant "Virtue is the strength of a human being's maxims in fulfilling his duty." (Kant167). This idea of virtue will be explored in concordance with the position I defend.

4 Even Kant, who's ethical system does not rely upon a definition of happiness, he explored the topic, according to Kant:

Happiness is the state of a rational being in the world, to whom everything in all of may attempt to provide a modern perspective on how our minds are the actual main highways to happiness.

\section{Epictetus, stoicism and the early philosophy of mind}

It can be conceived at the light of the modern philosophy of mind, that the ancient Greeks (and Romans) did not have a solid theory of the intentionality ${ }^{5}$, or a complex metaphysical

his existence goes according to wish and will. Hence this depends upon the agreement of nature with his entire purpose [which includes happiness], likewise to the essential determination basis of his will (Kant 161)

However, this definition of happiness is entangled with the moral system that he develops. In other words, it can be suggested that Kant holds the idea that happiness is what makes a balance with morality of rational beings. Thus, as Kant suggested "[happiness] amounts to the highest good of a world into which... we must definitely transfer ourselves" (Kant180). I may agree with Kant in some sense, as he emphasizes that happiness must be grounded in a more moral conception, and this moral conception must be rooted in the reason. Thus, happiness must be part of our mental faculties, rather to considered happiness as a result of external objects alone.

5 Intentionality in the "modern" conception can be traced back to Franz Brentano (1874), so intentionality will be defined in this line, that is to say, a representation or aboutness. Nowadays, we understand representation under a theory of intentionality, introduced in contemporary philosophy by Franz Brentano, who claims that:

Every mental phenomenon is characterized by what the Scholastics of the Middle Ages called the intentional (or mental) inexistence of an object, and what we might call, though not wholly unambiguously, reference to a content, direction toward an object (which is not to be understood here as meaning a thing), or immanent objectivity. 
and epistemological theory on the mind as we currently have. Instead, the Stoics conceived different ideas to explain representation. Nonetheless, it is important to emphasize the fact that the views that they had, can be

Every mental phenomenon includes something as object within itself, although they do not all do so in the same way. In presentation something is presented, in judgement something is affirmed or denied, in love loved, in hate hated, in desire desired and so on. (Brentano 68)

Brentano attempts to find what is the mark of the mental, this is, he developed a kind of dualism to determine what exhibit a what cannot exhibit mentality. Although I will not follow this line of research, it is important to mention to fully understand the idea behind Brentano's thesis. The idea of intentionality is attached to the idea of content, thus, for every intentional state, there is something that state is directed, hence, intentionality has been called "aboutness" or "directedness", in other words, if I represent an apple, the intentional state is related to the apple. Of course, I can represent a unicorn even if I haven not see one. I can represent non-exist objects. But what are our attitudes toward the object, in other words, if we have a brain state that realize a given phenomenology, and this realize intentionality, how is our external reaction? What I am claiming, in line with the Stoic position, is that our mental states are physical as well, and yet the difference is that nowadays a full scientific explanation can be given. This is a matter of adjust the metaphysical framework that science may understand how the mind is and how it works. This is not something easy, but a very good approach to explain the metaphysical nature of mind is through a non-reductive physicalism, inspired in the words of Putnam (Putnam, 1967), Fodor (1974) and David Lewis (1966). What is important to mention about this, is that the mental states are physical, but not reducible to a physical property. Having this framework, and in line with an analytic functionalism, one can explore the idea of what plays the role of the functional states, this, what could be the content of mental states, and such role is playing by folk psychology. understood from the perspective of the modern philosophical concepts. As suggested by Rubarth, from the Stoics and the theory of representation, it can be conceived a theory of phenomenal experience (Rubarth, para. 8). However, what it is important to emphasize is that the views on representation and phenomenology (according to the Stoicism) must be part of a physical process, determining the physicalism as the starting point.

The Stoicism emphasizes the idea that everything is physical ${ }^{6}$. In their conception, even the mind (soul) has a physical nature. This by no means suggests that the Stoics had an adequate physicalist explanation of the mind as it was determined by the "scientific" conceptions of their time. For instance, the Stoics suggest that the soul has its sit on the heart (Peters 78), and this "soul" (identified with the word pneu$\mathrm{ma}^{7}(\boldsymbol{\pi v \varepsilon \tilde { \boldsymbol { v } } \boldsymbol { \mu \alpha } )}$ is just oversees all the

6 This idea is supported by Quine for example, who claims that "the physical facts are all the facts" (Hookway63). However, there could be a problem with the view: the reduction, this was not considered by stoicism, and yet, Quine may endorse about the mind a view practically in line with the anomalous monism of Davidson.

7 Even if it is not the aim of this paper, the word pneuma belongs to a broad concept that may refer the mind -or the soul - for example. Some of the words are pneuma, psyche, spirit, anima, ghost. And as has been point out, the Stoics use the word pneuma as soul, and in the context of a materialist explanation of cognitive faculties. 
cognitive process ${ }^{8}$. The Stoics used the word hegemonikon to explain the idea on how all the physical faculties are governed by a single entity. As Rubarth suggests, "as a highly sensitive substance, pneuma pervades the body establishing a mechanism able to detect sensory information and transmit the information to the central commanding portion of the soul in the chest. The information is then processed and experienced" (Rubarth, para. 17). As a result of this initial explanation, it can be concluded that the Stoics needed to find (1) a way to explain how the information is experienced, (2) a way to explain how and why the external events can affect us, and (3) to propose a way to deal with those external events. To put this in another way, a physical idea of "mind", the idea of the perception, and the content of perception must play a fundamental role in the Stoicism, therefore to happiness, and all of this can be analyzed in terms of philosophy of mind.

A clear example of this is found when Epictetus declares, "Make it, therefore, your study at the very outset to say to every harsh external impression, "You are an external impression and not at all what you appear to be" (Epictetus 10). Epictetus suggests that it is the perception of the thing, and the narrative of such event what influence

8 I will return to this point shortly, not all the Stoics may agree with this claim. us. If a physical object hits us, our perception may not be the result of a direct contact with the object (direct realism); instead, our perception is indirect (indirect realism). To put this in another way, this kind of perception needs an explanation on how the phenomenal properties are realized by the relevant states of the brain, and by the history of evidence and the cognition of the agent. This conceptualization explains the reason why the Stoics required a physical and a (more or less) refined explanation on how the object affect us based on the representation that we have (with a linguistic content). Without such explanation, the whole position of the Stoicism would be pointless. Therefore, the only way they had to explain the matter was by appealing to mere physical terms of the mind. Thus, the idea behind the Stoicism is to account a physical explanation of the mind allowing some relations with the physical objects in the word. By doing this, and with an epistemological and metaphysical inquiry about the nature or reality, they are prone to present their ethical consequences a theory of happiness, rooted in the way things appear to us. In other words, the stoics developed a very complex and interesting account of representation, in modern terms, intentionality.

According to the Stoic philosophy, the hegemonikon as was explained before, controls all the physical faculties. As 
Julia Anas suggests, "Content is dominant in Stoic philosophy of mind...encourages them to focus on the content of experience rather on its phenomenal qualities" (63). On this account, as the soul responds to a physical explanation, the hegemonikon oversees all the representations, and in order to have a representation, it is essential the content. However, the main point of discussion lies in determining if in contemporary terms, the phenomenal qualities play a central role in any Stoic interpretation of happiness. Seddon has noted that, "the Stoic sophos (wise person) is to learn what is 'in one's power', and this is 'the correct use of impressions' (phantasia)" (para.18). This insight would lead the person to reach a tranquility of mind or ataraxia. This phantasia could be understood in phenomenal terms rather than in merely representational ones.

Let us look at the modern ideas of representation. Tim Crane claims that all the representations must have a content, but regarding the phenomenal experience, he observes that the "experience might be representational without being a propositional attitude" (Crane 469). Here it is evident that Crane's position is a representationalism in which the phenomenal content is a kind of representational content (Tye 68). For this reason, if we could relate the Stoic position with a modern view, it could be conceived as a representationalist one.
However, I will not endorse this viewpoint yet. First, and as I explained in my doctoral thesis, according to Tye, the phenomenal character can be explained in terms of representation. In his words, "the phenomenal character is one and the same as a certain type of intentional content" (137). He suggests that, when a red apple is observed with good light and optimal conditions in the supermarket, the visual experience is directly related to the apple. The color of the apple constitutes the representational content (which is one of the physical properties of the object), the phenomenal character of the experience of the red apple (its redness) is present only by virtue of a characteristic such as external property, such as its redness (as suggested in the argument of transparency (Harman) Consequently, the property entails the phenomenal character of seeing red (Gonzalez 77). However, if according to the Stoicism the mind can be considered as physical, and the hegemonikon oversees all the representations, today's representationalism may not suit as a theory to explain the central role of the phenomenal experience in a theory of happiness. I will elaborate this idea more in detail.

\section{The role of the phenomena experience}

In my opinion, the representationalist argument for the phenomenal experience and intentionality may not 
be precise. It seems to me that the phenomenal experience is what determines what we represent ${ }^{9}$. Having said that, it is worth noting that according to Stoicism, "appearance"10 is what the information of our senses presents to us. As Annas admits, "what we receive is itself called appearance (phantasia)" (Annas 66), suggesting a kind of representationalist approach to understand Stoicism. However, this appearance must not be the result of a transparency (Harman, 1990), neither a direct realism account of perception as it has been pointed out. Let us explore this idea more in depth.

If we compare the modern ideas of representationalism with the Stoicism, we may notice that the role assigned to the phenomenal character of experience by the stoicism is unclear. My own view of this is that the perceptual process ("appearance") is not enough

9 For a reference about the phenomenal intentionality program can be consult: Kriegel (2013), Mendelovici (2018), Gonzalez (2018)

10 Contemporarily, Uriah Kriegel develops a framework to explain the phenomenal properties, and he suggests that "Corresponding to every perceptible property, then, is an appearance property, or phenomenal property. The appearance of an object is determined by the set of all its phenomenal properties." (Kriegel, Phenomenal content 183) but later he adds that "...the phenomenal character of experience is given by the phenomenal properties represented by experience." Kriegel still hold a kind of representationalist view, however, he is clearly enough to suggests some internal nature of the phenomenal properties, accordingly, this could be a path to follow de defend a stoic view of mind in representationalist terms without exhaust an internal view. to determine the whole history of phenomenal experience and representation held by the Stoicism. Even if the representation to the stoicism is, in Annas words, "...experienced by the perceiver as something with content" (72), this is not enough to determine the whole representation of an object. Now, it is necessary to emphasize the fact that both (the Stoic view and in my view) are physical events. This permits to explore the representation as a property of the mental states realized by a given brain state if the appearance is the way something appears to someone, this needs to be performed by a physical substrate like the brain.

I should insist that this appearance must be based on phenomenological ways. Why? As I explored in my doctoral thesis what it is relevant of our phenomenology is the brain state (Gonzalez chapter 2), not the representational content, in other words, with a theory of perception base on an indirect realism, can be explored the idea that what we are aware are the phenomenal properties of the object, and indirectly the object itself, the phenomenology just put boundaries to our representation. With this view, the phenomenal experience must play a role in a theory of happiness rooted in the way our mental states are realized by the brain. This is what it is required with a stoic point of view, as philosopher Julia Annas admits that, "Even if the early stoics understood 
the perception as an "imprint", like the "imprint of seals on was" (73) clearly suggesting a direct realism, that let us also think in a transparency argument as (Harman did) as foundation of a theory of representation to stoicism, but this is not correct according to my view. However, Chrysipus will lead us to an absurd because an object could have different shapes simultaneously, this insight, however, reminds the one objected by Jackson in the adverbial theory of perception ${ }^{11}$. To this extent, the perception for the Stoicism is a process. Even if Annas insists that for stoicism "whereby things are represented to the agent in various phenomenologically different modes" (73), this phenomenology does not play the role that I try to follow. Accordingly, representations alone (early stoicism, and contemporary representationalism) may not be enough to explain metaphysically the nature of happiness. In other words, if the phenomenology (as I suggest) plays

11 The adverbial theory of perception is a kind of direct realism theory It suggests that we are in a direct contact with the object of perception, as Crane and Craig claim, "An important objection to the adverbial theory has been proposed by Frank Jackson (1975). Consider someone who senses a brown square and a green triangle simultaneously. The adverbial theory will characterize this state of mind as "sensing brownly and squarely and greenly and triangularly". But how can it distinguish the state of mind it is describing in this way from that of sensing a brown triangle and a green square?" (Crane et. al, para. 17). This argument was followed by Chrysipus to use rather to imprint "alteration" and define that an appearance is an "alteration of the soul" (Annas 73). a fundamental role in the psychological explanation of stoicism, and this is conceived as a physical process, then an internal explanation of the phenomenology should be required ${ }^{12}$. However, as appearances and assents involve content, it seems to be clear that the phenomenological interpretation of the Stoicism must be determined by a linguistic content, rather to a mere perception, and I may agree with this view.

This point worth to be discussed. According to Annas, "[to stoicism] perceiving is thinking, not the reception of raw data" (Annas 755). In this sense, if what we know about the Stoics is true, the language is required to think, and therefore, it cannot be a phenomenology without language ${ }^{13}$, thus, the perception of the object will require of the language to add color to our representation, otherwise representations would be simple shadows. Epictetus endorses this view by declaring:

Men are disturbed not by the things which happen, but by the opinions about the things; for example, death is nothing terrible, for if it were it would have seemed so

12 This of course will lead to a problem in modern times, mostly the explanatory gap and the consciousness hard-problem.

13 To clarify this aspect, when I suggest that what it is relevant to phenomenology is the brain state, is in part because, and the fact that we can apply phenomenal concepts to our introspection, in this way a conceptual view of phenomenology can be conciliate with the stoicism. 
to Socrates; for the opinion about death that it is terrible, is the terrible thing. When then we are impeded, or disturbed, or grieved, let us never blame others, but ourselves--that is, our opinions. It is the act of an ill-instructed man to blame others for his own bad condition; it is the act of one who has begun to be instructed, to lay the blame on himself; and of one whose instruction is completed, neither to blame another, nor himself (20).

What Epictetus may suggest is that rationality and thinking are tied with the use of the language. Let us remember that the hegemonikon is where all the perceptions happen. This mean that in the case of pain, even if the source is in some part of the body (the foot for example), the "sensation" of pain will be located in the hegemonikon, this lead to some stoics to discuss the idea that perhaps the hegemonikon is in the head ${ }^{14}$. Having said this, it may be worth noting that Chrysippus had to follow a kind of folk psychology as Annas had suggested; with this view, I follow suit: the thoughts of Epictetus and the Stoicism could be analyzed in terms of a more propositional approach, this is, based on a theory of propositional attitudes and folk psychology. Hence some insights into the idea of phenomenal concepts and propositions

14 This may suggest by the fact that Diogenes of Babylon discusses the idea held by some Stoics that the hegemonikon was in the head (Annas 61). will determine the linguistic content to the phenomenology realized by the brain states when we experience the objects of perception ${ }^{15}$. Consequently, an emotional response may be expected, and this response may be visible in our behavior.

\section{Happiness as a propositional attitude}

Precisely, I will point out that the idea of the content of a mental state can be studied under the view of propositions. Furthermore, I agree with the idea that what makes the content an intentional mental state is the proposition, but this idea would be true only once a phenomenology is realized. Although the Stoics did not have a complex theory of proposition and the relation between a mental state and language, it has been suggested that the Stoics developed the concept of lekton to link their epistemological, metaphysical, and logical views with the "external objects of the world". As Julia Annas notes:

Lekta are conveyed in language; in our minds, they are conveyed in a language of thought. Perception in humans involves lekta, since it involves receiving an appearance

15 Let us remember again, that via indirect realism of perception we have an awareness of the phenomenal properties realized by the brain states, this is, we have a direct contact with the object via its phenomenal properties, and indirectly with the object itself. 
which is a rational appearance, one containing propositional content, and also involves assent to the lekton expressing the content of that appearance. Perception, in other words, may be an experience with a certain kind of phenomenological feel, but more importantly it is reception of and commitment to information about what is perceived. In perception, only one kind of lekton is involved, namely, statements or axiomata (35).

And if this language of thought can be associated with the modern conception held by Fodor, then our simple representations might form some more complex ones. Thus, simple representations can include symbols (lekta in stoicism) that allow a relation between the subject and the mental representation. Marina Rokova observes that, "the language of thought allows to assign properties to objects that characterize all kind of representations" (101), implying the language as the entity that not only shapes our mental states, but also, the way we introspectively make relations between the objects and the content. To put this in another term, let us explore the language of thought championship by Fodor; if the language of though explored by Fodor is accurate, then we would not need necessarily a picture -in intentional terms - in our minds in order to have a representation, just a concept. For instance, if I think there are some kids in the playground, I do not have the need to think in a specific number of kids. In the same way, if I see someone mourning a dead, I do not have the need to think about the body lying in the coffin. I just need the thought of a dead, which is according to Epictetus what would cause and effect on me, nonetheless, I emphasize that this though via language is intentional and phenomenologically-grounded.

Let us examine another an example. Some days ago, I was in the veterinary with my dog. A lady enters the reception and asks the veterinary about her dog. The veterinary tells her that the dog just died. It was a dog that live about 14 years! The lady starts crying. During that moment, my first though was not about the dog lying in the veterinary. I just had the thought about the lady's suffering and the good times she shared with her dog. In this manner, to represent the whole history in my mind, I need first to phenomenologically thing about the dog, apply phenomenal concepts, and to represent all the aspects associated to the dog. Once this process is done, I may be able to make a judgment about the suffering of the lady. In other words, in order to have a modern interpretation that fits Stoicism, it must be in line with a phenomenal-intentionality program. In this case, the phenomenology is 
more primitive than the intentionality; the former is realized by the relevant brain state, the latter is realized by brain states as well, however, it obtains its linguistic content once the phenomenology is realized -via phenomenal concepts-.

For instance, when I saw the lady crying, I phenomenologically grant to this fact a content, but this happens only if I have a history of evidence and cognition that allows me to understand the symbols associated with it. In concrete, the pain that can produce the loss of a loved dog, and from there, to have any sort of desires, beliefs, and fears that may affect me can be only understood if I have an history with a dog. Yet, as I saw the lady crying, I started thinking about my own dog and the fact that he was fine but having into account that he could die at any moment. David Lewis's scheme may allow to better illustrate the point:
I could fear of the dark, because I have the evidence that something terrible may happen if lights go out; however, some other person may not experience such a thing and may not be afraid of the dark. Therefore, what affect us will depend upon our history, and on the way our phenomenology determines our representation of the objects, facts, or persons in the world. Consequently, this whole evidence needs to be determined by a linguistic framework, this is the way we conceptually understand our phenomenology and representation.

Having said that, we may ask why is this possible? It is possible because we require to experience things to determine the boundaries of the representation; otherwise, the position would follow a representationalist account of mind, but such a theory may not work, because what is required is to understand how, by the chain of events that impact our senses, this information is driven by different neuronal

\section{P Ao}

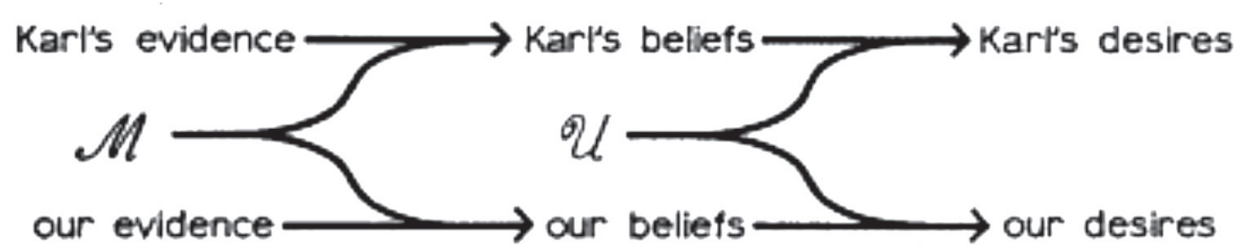

Taken from David Lewis Radical Interpretation, 1974 
channels, ${ }^{16}$ until the phenomenology is ultimately realized ${ }^{17}$. In this manner, it may be suggested that the Epictetus ideas behind representation are by far more complex than the simple idea of representation that a initial reading may suggests. Bearing in mind the previous points, what it is certainly worth to explore is if the Stoic viewpoint of Epictetus can be supported. This could be achieved by demonstrating if the propositional attitudes play a fundamental role in our mental state; therefore, in our behavior.

Let us return to the propositional analysis. If in the Epictetus point of view, our concerns are about the representation itself, but not about the thing being represented, it can be suggested that what establishes a link between our worries and the object is

16 Recently a very promising research in neuroscience has determined that subjective happiness can be observed in the activation of a brain area called the precuneus. This area that has been associated with memory and consciousness, has a very fundamental role in happiness. Moreover, the study suggests that an amount ofgrey matter in this area may increase happiness (The structural neural substrate of subjective happiness (Wataru Sato, Takanori Kochiyama, Shota Uono, Yasutaka Kubota, Reiko Sawada, Sayaka Yoshimura\& Motomi Toichi, 2015) Thus, the whole history of stoicism may be put in perspective: with a metaphysical framework to understand the mind, the findings could be used to determine the internal nature of happiness.

17 This metaphysical view is rather in a non-reductive physicalism, otherwise a reductionism may erase our phenomenology as Smart (1959) suggested, and Churchland or Dennett may defend via materialism eliminitavist. a proposition. For example, the proposition "Elisa fears that it will rain", implies the attitudes; a psychological relation such as belief, desire, fear or hope that a subject carry with a proposition. Hence, what it is important to emphasize is that the attitudinal component of a propositional attitude is a matter of how a proposition is being taken. In this view Elisa can believe that it will rain, hope that it will rain, fear that it will rain, and so forth. In each case the proposition is the content of her attitude, the fear that it will rain, is the same. However, Sally, a friend of Elisa may think that the rain will ruin the whole day because she will not be able wear her new outfit. What differs in this case is how this proposition is taken by Sally (believed in, hoped for, or feared). And this is the interpretation in which the base of Epictetus must be translated. In addition to this, Epictetus claims that:

When you see a man shedding tears in sorrow for a child abroad or dead, or for loss of property, beware that you are not carried away by the impression that it is outward ills that make him miserable. Keep this thought by you: What distresses him is not the event, for that does not distress another, but his judgement on the event. Therefore, do not hesitate to sympathize with him so far as words go, and if it so chance, even to groan with him; but take heed that you do not also groan in your inner being. (Epictetus 20) 
But how is it possible to have a judgement of the event? How can we judge that someone is in pain, distress, suffering, misery or agony? If we see somebody crying, we may assume that the person is in pain or suffering, if we see somebody laughing, we can infer that the person is happy. This is possible nor by a principle of humanity neither via an interpretivism. How can we explain the mental states in us and in others?

Firstly, according to the functionalism, beliefs, desires, hopes, fears (among others) are mental states because they play a given role in the cognitive system. Now, these roles can be grounded in the scientific theory as Smart suggests, however, this reductive explanation, is by no means satisfactory. Rather, the position of David Lewis as sympathetic with a physicalist account of mind. He suggests that what plays the role in our mental states is the folk psychology. Wolfgang Schwarz declares that:

Lewis held that psychological states are individuated by their causal-functional profile. Pain, for example, may be characterized as whatever state is typically caused by burns and injuries, causes suchand-such signs of distress, a desire for the state to go away, and so on. If it turns out that some biological state, say C-fibre firing, uniquely plays this role, then it has turned out that C-fibre firing is pain. According to Lewis, the roles that characterize mental states can be extracted from folk psychology: our tacit but shared beliefs about how mental states interact with one another, what kind of behavior they tend to cause, and how they change under the impact of perceptual stimulation. Folk psychology implicitly defines our mental vocabulary: 'pain', 'hunger' etc. mean 'whatever state plays this and that role' (504).

It is worth remembering that Lewis has a view in which functionalism (analytic-functionalism) is based on material metaphysics. And as result of that, it can be suggested that if this modern view of physicalism can be equated with the views hold by the Stoics, then a contemporary account of philosophy of mind can explain successfully the view of happiness that Epictetus holds. In this use case, the relation by linguistic means that we have with the representations (phenomenal properties that injects intentionality into the world).

Hence, if the relation with the proposition by means of the attitude can be changed, our relationship with the object can be different. In other words, rather to say, if I fear that it will rain, a stoic way to handle the adverse weather may be by changing the attitude toward the proposition, 
"I hope that it will rain". As Epictetus acknowledges, we cannot change the fact that it will rain; however, what we can change is our representation and the attitude towards that event. Moreover, Spinoza claims that, "From what has been said we may clearly understand the nature of Love and Hate. Love is nothing else but pleasure accompanied by the idea of an external cause: Hate is nothing else but pain accompanied by the idea of an external cause" (1980, 0.163). Spinoza in the same way as the Stoics, suggests that our emotions are ideas -representations - of external causes. What we could do is to change our narrative, our linguistic tools to confront the situation, because there are not, according to the Stoicism, "perceptions which do not involve conceptualization and thinking..."18 (Annas 78). Yet, this only can occur once the phenomenology is realized. Tn this manner, the intentionality is injected into the world.

Once again, let us underline the fact that to the Stoicism the appearance is rational. This with a thought that realizes the content articulated

18 Indeed, as Patricia Kitcher suggests, Kant may defend and idea of concept, as she claims that "Intuitions are singular representations that relate directly to objects; by contrast, concepts are general representations that relate to objects only trough relating to intuitive representation" (Kitcher, 2017). In other words, concepts may be required to unify cognition, in this sense, concepts in Kant may play the role of the hegemonikon. by language. Therefore, it can be suggested that what plays the role of this though is folk psychology. In words of Schwartz, "a desire of happiness can be manifest in all kind of behavior, depending on what else the subject believes and desires" (504). A belief plays a fundamental role, and if this role is given by folk psychology, we react to external events in a way determined by the way we believe the things that we believe. In other words, most of our attitudes toward external objects can be determined by the justifications that we may have; however, it may be the case that most of our beliefs are not justified. And so, epistemologically, our happiness must depend not on the external objects themselves, rather than in the justification of the beliefs that we have. To have a desire of happiness, we must justify our beliefs, and consequently, a more accurate representation. In this situation, instead of believing that cancer is a direct ticket to paradise -or hell - we could justify our knowledge about death in a different way, and thinking about the cancer in a different way, with a different narrative.

Let us go back to the Stoic conception. According to Rubarth, "Assent occurs when the mind accepts a phantasia as true (or more accurately accepts the subsisting lekton as true). (párrafo 36), thus, the judgment referred to Epictetus consists on merely 
opinions. Therefore, the change in the narrative suggested by Epictetus must be in line with the acceptance that epistemologically we must prove our phantasies. As the ancient philosopher admits: "It is not the things themselves that disturb men, but their judgements about these things" (Epictetus 4). Again, according to stoicism, in order to have an epistemological access to our minds, we must have first a linguistic framework. Hence, a more contemporary approach to our beliefs, and how such beliefs play the role via folk psychology in our functional states (not linguistic brute facts as the Stoics hold), can clarify the way we can reinterpret reality in our favor.

Equally important, this viewpoint is not exempt of critics. Patricia Churchland argues that folk psychology and propositional attitudes are replaced by neuroscience. Daniel Dennett (1996) believes also that we confer intentional states to other people or animals based on the principle of humanity. In his view, we do not know their intentional states, because we do not have them. We just make an interpretation of our mental states. However, we cannot simply deny mental states. Both philosophers deny mental states to avoid the metaphysical and epistemological problems by recurring to a reductive account. Metaphysically speaking, this can avoid by exploring further a non-reductive physicalist view and an indirect realism. This problem is mostly avoided because of old-fashioned metaphysics and problems related to skepticism. Nevertheless, if the metaphysical framework to explain our mentality is a reduction, we are in a dead end. Consequently, a metaphysical theory of happiness based on the nature of the mind could be hard to defend -unless a kind of representationalism can be granted. However, as I have explained, the representationalism is not a correct way to interpret the mind.

The ideas that the Stoicism and Epictetus defend can be further discussed on the light of a non-reductive physicalism and the view based on analytic functionalism. Sadly, there is no room to discuss the base of such theories in detail here; however, it is worth to say that our perceptions, our mental states rooted in the brain states play a crucial role in determining that happiness, is not limited to some just external objects that carry any given information. Instead, happiness must deal also with how such information is processed in our brains, and then how our phenomenology realized by such brain states recreates the objects.

Indeed, the history of cognition, social, economic, linguistic and other factors of an agent determine the way that the information is transformed. They impact our epistemological 
relation with the world; therefore, our judgements or passions toward the world. For this reason, what Epictetus suggests is that what we can change is our narrative, the things that affect us product of the way that our senses provide us information (phantasia). This is possible because our phenomenological experience and representation is something that may depend upon us, rather to think that happiness is determined by external objects or that the objects themselves provide the content via transparency. Therefore, the idea to explore a metaphysical framework based on the contemporary ideas of analytic-functionalism, a non-reductive physicalism, and a theory of folk psychology, are the actual departure points to explore and understand one of the most elusive tasks of the human being: the nature and pursuit of happiness.

\section{Bibliographical References}

Annas, Julia. Hellenistic Philosophy of Mind. Los Angeles: University California Press, 1992. Printed

Brentano, Franz. Psychology from an Empirical Stand Point (Second ed.). New York: Routledge, 1995. Printed

Craig, FredandCrane, Tim. The Problem of Perception. n.d.Web. Retrieved, 20th March, 2019 from <https://plato.stanford.edu/ cgi-bin/encyclopedia/archinfo. cgi?entry= perception - problem $>$

Crane, Tim. "Is perception a propositional attitude?". The Philosophical Quarterly. 59.236 (2009): 452 469. Printed

Dennett, Daniel. Kinds of Minds. New York: Basic Books, 1996. Printed

Epictetus. Discourses. Translated by W. Oldfather. Harvard University Press, 1925. Printed

Fodor, Jerry. "Special Sciences (or: the disunity of science as a working hypothesis)."Philosophy of mind, classical and contemporary readings. Ed. D. Chalmers. Oxford: Oxford University Press, 2002. 126-134. Printed.

Gonzalez, Allan. On the phenomenal, intentional and physical nature of mind. Keele, 2018. PhD. Thesis. Printed

Harmann, Gilbert. "The Intrinsic Quality of Experience". Philosophical Perspectives, 1990. 31-52. Printed

Hookway, Crhistopher.Quine. Cambridge: Polity Press, 1995. Printed

Kant, Immanuel. The Metaphysics of Morals. Translated by L. Denis, Ed. and M. Gregor. Cambridge: Cambridge University Press, 2017. Impress. Original work published in 1785. Printed

Kitcher, Patricia. "A Kantian critique of transparency." Kant and the Philosophy of Mind: Perception, 
reason, and the self. Ed. A. G. Stephenson. Oxford: Oxford University Press, 2017. 158172. Printed

Kriegel, Uriah. "Phenomenal content”. Erkenntnis. 57. 2, 2002: pp. 175-198. Printed

Kriegel, Uriah. "The phenomenal intentionality research program". Phenomenal Intentionality. Ed. U. Kriegel. Oxford: Oxford University Press, 2013. Printed

Lewis, David. "Radical interpretation". Synthese, 27. 3-4, 1974, pp. 331-344. Printed

Lewis, David. "Psychophysical and theoretical identifications". Philosophy of Mind Classical and Contemporary Readings. Edited by D. Chalmers. Oxford: Oxford University Press, 2002. 88-93. Printed.

Mendelovici, Angela. The Phenomenal Basis of Intentionality. Oxford: Oxford University Press, 2018. Printed

Peters, Frederick. Greek Philosophical Terms. New York: New York University Press, 1967. Printed

Putnam, Hillary. "Psychological predicates". Art, Mind, and Religion. Edited by W. H. Merrill \& W. H. Pittsburgh: University of Pittsburgh Press, 1967. 78-89. Printed

Rasmussen, David. "Human flourishing and the appeal to human nature". Social Philosophy and Policy, 1999. 1-43. Printed
Rokova, Marina. Philosophy of Mind A-Z.Edimburgh: Edimburgh University Press, n.d. Printed.

Rubarth, Seldon. The Internet Encyclopedia of Philosophy. n.d. Web. Retrieved 15ht March, 2019, from <https://www.iep. utm.edu/stoicmind/\#SH3b>

Schwarz, Wolfgan. "Analytic Functionalism". A Companion to David Lewis. Edited by B. L. Schaffer. Oxford: John Wiley \& Sons, Inc, 2015. 504 - 518. Printed.

Seddon, Kirch. Epictetus. n.d. Web. Retrieved 16th March 2019, from https://www.iep.utm.edu/epictetu/

Spinoza, Baruch. The Ethics, Demonstrated in Geometrical Order. Retrieved 20th March 2019, From https://www.faculty.umb. edu/gary_zabel/Courses/Spinoza/Texts/Spinoza/e2c.htm

Trianosky, Gregory. "Natural Affection and Responsibility for Character". Identity, Character, and Morality. Edited by O. F. Rorty. Cambridge: MIT Press, 1990. 93-109. Printed.

Tye, Michael. Ten Problems of Consciousness: A Representational Theory of the Phenomenal Mind. Massachussets: MIT Press, 1995. Printed.

Wataru Sato, TakanoriKochiyama, Shota Uono, Yasutaka Kubota, Reiko Sawada, Sayaka Yoshimura \& MotomiToichi. "The structural neural substrate of subjective happiness". Nature, 2015. 1-7. Printed. 
